\title{
Field-of-study mismatch and overqualification: labour market correlates and their wage penalty
}

\author{
Guillermo Montt
}

Correspondence: montt@ilo.org Research Department, International Labour Office, Route des Morillons

4, 1211 Genève, Switzerland

\begin{abstract}
Field-of-study mismatch occurs when a worker, trained in a particular field, works in another field. This study draws on the Survey of Adult Skills (PIAAC) to explore how skill supply and labour market demand dynamics influence mismatch. It updates cross-national estimates on mismatch and estimates the mismatch wage penalty. Findings suggest that around $40 \%$ of workers are mismatched by field at their qualification level, $11 \%$ overqualified in their field and 13\% overqualified and working outside their field. The saturation of the field in the labour market and the transferability of the fields' skills predict the incidence of field-of-study mismatch and overqualification. Workers who are mismatched by field only suffer a wage penalty if they are overqualified.
\end{abstract}

JEL Classification: J24, J31

\section{Introduction}

Field-of-study mismatch occurs when a worker, trained in a particular field, works in another field (e.g. a worker trained in the law, business and social sciences field works in the service sector, or, as Sloane (2003) illustrates, that of an English major working as a statistician). Conceptually and empirically, field-of-study mismatch is distinct from qualifications mismatch in that a worker may be matched to the job in terms of the quantity of schooling received (qualification match) but not by the type of schooling received (Sloane 2003; Robst 2008; Quintini 2011a). Seen this way, field-of-study mismatch is a form of horizontal mismatch while qualification mismatch is a form of vertical mismatch (Verhaest et al. 2013). In studying field-of-study mismatch, the literature has generally ignored how skill supply and skill demand dynamics influence mismatch and the relationship between horizontal and vertical mismatch in the wage penalty associated with field-of-study mismatch. Using the Survey of Adult Skills (PIAAC), an internationally comparable survey of adult skills, this paper addresses both gaps and updates cross-national estimates of field-of-study and qualification mismatch.

\section{Background}

Field-of-study mismatch occurs when a worker, trained in a particular field, works in another field. Also referred to as horizontal mismatch, it is distinct from qualification (vertical) mismatch in that a worker may be matched to the job in terms of the quantity of schooling received

(c) The Author(s). 2017 Open Access This article is distributed under the terms of the Creative Commons Attribution 4.0 International License (http://creativecommons.org/licenses/by/4.0/), which permits unrestricted use, distribution, and reproduction in any medium, provided you give appropriate credit to the original author(s) and the source, provide a link to the Creative Commons license, and indicate if changes were made. 
(qualification match) but not by the type of schooling received (Sloane 2003; Robst 2008; Quintini 2011a). Field-of-study mismatch may be one of the reasons behind qualification mismatch (e.g. if there is no work in their particular field, jobseekers may have to downgrade to find a job), but only a part of field-of-study mismatch can be considered qualification mismatch (Ortiz and Kucel 2008; Quintini 2011a; OECD 2016).

Workers' qualifications and field-of-study are proxies for their skill set. They are imperfect indicators of the more specific skill mismatch, whereby workers' actual skills are measured against the specific skill requirements of the job (Levels et al. 2014). Despite research development to advance the measurement of skill mismatch (e.g. Pellizzari and Fichen 2013; OECD 2016) an internationally comparable and sufficiently broad assessment of skill mismatch remains an area for future work (CEDRA 2009). Research attention to qualifications and field-of-study mismatch remains relevant, as workers' specific skills are high to identify in the process of selection and recruitment. Qualifications and field-of-study remain relevant indicators of worker skills given the fact that sorting hinges on these two signals. For specific applications of field-of-study in the context of skill mismatch, see, for example, McGuinness and Sloane (2011), Garcia-Aracil and van der Velden (2008) and van de Werfhorst (2002); for discussions on qualification mismatch and its relationship to skills, see, for example, Levels et al. 2014, Quintini 2011b and Chevalier 2003.

Hartog (2000) uses human capital, job competition and assignment theories to frame overqualification and the relationship to wages. This framework can be applied to fieldof-study mismatch. From a human capital theory perspective, firms will adapt their production process to changes in the relative supply of labour. Any mismatch, including field-of-study mismatch, is temporary and firms will adjust their demand and productive process to the available stock of human capital. Job competition theories argue, in contrast, that workers line up in the hiring queue-according to their educational credentials and field-of-study, or other criteria relevant to employers for the purposes of sorting jobseekers for the available vacancies-but it is the characteristics of the job that determines the productivity of the job, not the human capital stock of the employee. In the job competition model, field-of-study mismatch is a result of employers in a particular occupational group requiring more workers than available in the corresponding field, thus having to draw workers from further down the queue, reaching those that come from different fields. In job competition theory, field-of-study mismatch can also result from employers downplaying field-of-study as a relevant signal in the hiring process. Importantly, as workers' productivity depends on the characteristics of the job, in job competition theory, there should be no wage penalty associated with field-of-study mismatch (or any other type of mismatch thereof).

The empirical evidence supports a third, intermediate model: assignment theory. In it, the productivity of a job and the allocation process depend on both demand and supply factors (Sattinger 1993). They specify that workers' income or utility maximisation guides workers to choose particular jobs over others, but, in equal importance, jobs or groups of occupations available to workers and the mechanism that assigns workers to jobs need to be considered. Thus, for a particular job, certain workers will have more advantages (as a result of their general and job/field-specific skills acquired in formal training) than others, but these jobs may or may not be available to them, possibly pushing them to choose other jobs or fields instead. Assignment theories predict that productivity (and wages) will depend on the quality of the match between the 
job and the worker and that the likelihood of a field-of-study match will depend on both the skill demand in a particular occupational group and the supply of workers from the corresponding field.

Assignment theories thus effectively predict that mismatched workers by field-ofstudy will suffer a wage penalty by virtue of their lower productivity (i.e. their lack field-specific skills) or higher costs (i.e. need to acquire field-specific skills) than their well-matched peers and that, as workers acquire experience in the field of their jobs (and field-specific skills), the quality of the match between their skills and their job requirements will improve and so will their wages relative to their well-matched peers (Nordin et al. 2010; OECD 2014). A mismatched worker will not be able to use his/her field-specific skills on the job, and their employers will not reward these skills. Field-ofstudy mismatched workers are thus expected (and do in general) earn lower salaries when compared to their well-matched peers (Wolbers 2003; Robst 2007a; McGuinness and Sloane 2011), even after accounting for skill heterogeneity (Nordin et al. 2010) or qualification mismatch (Robst 2008). Field-of-study mismatched workers who are also overqualified are expected to suffer an even larger penalty.

Further, assignment theories suggest that the process of allocation of workers to jobs needs to consider both the supply and the demand of workers to understand field-ofstudy mismatch. This has motivated researchers to verify how firm characteristics relate to mismatch. Wolbers (2003) finds, for example, that field-of-study mismatch is more common among workers in small firms, those in the private sector and among those under part-time or temporary contracts. Robst (2007a, 2007b) acknowledges, but does not test, that accepting a job on another field-of-study depends on both supply and demand factors. Supply factors include the transferability of skills acquired in formal training in the particular field (with those degrees that have a higher emphasis on the provision of general skills-as opposed to job/field/occupation-specific skills-being more likely to promote out-field employment). Pay and promotion, career interests, working conditions, job location, family-related reasons and other preferences a worker has for different job characteristics are other supply-side factors predicting field-ofstudy mismatch. As such, workers with more cognitive or soft skills compared to workers in his or her field may choose a job in another field if occupations in the other field offer higher pay or better working conditions; workers with fewer skills may be crowded out in their field. Demand factors driving field-of-study mismatch refer to the fact that a job in the related occupational group may just not available.

Previous studies, however, have not included these supply and demand attributes in the analysis of field-of-study mismatch (a noteworthy exception, in the context of overeducation, is McGuinness and Pouliakas 2016). ${ }^{1}$ The general/specific orientation of the formal training received has been evaluated qualitatively and rather subjectively by mentioning that training in fields like the humanities are more general-oriented than those in health and welfare while observing that, coincidentally, field-of-study mismatch is higher among the former than the latter (Robst 2007a) or by respondent selfreports of the nature of the training received (Verhaest et al. 2013). But demand factors may explain the occurrence of this mismatch as well, as the availability of jobs in the humanities may be lower, relative to the number of graduates, than those in the health and welfare professions. The relationship between demand and mismatch has yet to be empirically tested. The joint occurrence of the transferability of skills in a given field 
and the demand for workers in that field has not been tested empirically, as most field-of-mismatch studies typically ignore the broader labour market context in which field-of-study mismatch takes place. A first exception is Wolbers (2003), who finds that mismatch is more common among workers who enter the labour market in a context of economic recession, pointing to broad demand factors, but does not analyse field-specific demand. The theoretical likelihood of the relationship between the labour market context and the likelihood of field-of-study mismatch is even clearer by acknowledging that employers rank field-specific knowledge as the most important attribute in determining a prospective workers' employability (Humburg et al. 2013), so the lack of employers in a particular field (irrespective of graduates' individual characteristics) will hinder graduates' employability because their field of specialisation is not aligned with the market demand for that field. A second exception to the consideration of labour market conditions in predicting mismatch is Verhaest et al. (2013) and Verhaest and van der Velden (2013) who find that business cycles explain the likelihood of overeducation that skill transferability explain the likelihood of both qualification and field-of-study mismatch. They also find a relationship between the labour market context (employment protection legislation, level of unemployment benefits and union bargaining power) and the likelihood of mismatch.

In attempting to find explanations for the occurrence of field-of-study mismatch, this paper proposes measures of field saturation and field transferability of skills-as proxies of skill demand and supply, respectively. It measures the levels of field-of-study mismatch across more than 20 countries and quantifies the wage penalties for workers in the presence or absence of qualification mismatch.

Previous studies have explored the individual-level correlates of mismatch by field-ofstudy. These findings show that mismatched workers are more likely to receive lower wages (Wolbers 2003; Robst 2007a; Kelly et al. 2010; Nordin et al. 2010; Quintini 2011b; OECD 2014), experience lower levels of job satisfaction and are more likely to be actively looking for a job while in the job (Wolbers 2003; Béduwé and Giret 2011). These findings are consistent with assignment theory (Sattinger 1993) as the wage penalty is stronger for individuals who report that their field-of-study is at a greater distance from the occupational group (Robst 2008; Nordin et al. 2010). Also, the wage penalty decreases with tenure in the job, in line with the assumption that mismatched workers earn job-specific skills in the workplace (Nordin et al. 2010).

Few of the studies that explore the individual-level correlates of field-of-study mismatch allow for comparable estimates across countries as they rely on self-reported mismatch mismatch (e.g. Robst 2007a, 2007b, 2008; Kelly et al. 2010; Nordin et al. 2010; Verhaest et al. 2013) or rely on relatively old data (e.g. Wolbers 2003; Quintini 2011b). Even fewer studies explore the correlates of field-of-study mismatch in conjunction with qualification mismatch (see, for example, Kelly et al. 2010, Béduwé and Giret 2011 and Kim et al. 2012 for noteworthy exceptions). The importance of accounting for qualification mismatch in analyses of the relationship between field-of-study mismatch and pay (or any other individual correlate thereof) is both statistical and conceptual.

Most graduates will hope to gain employment at the level of their qualifications and in the field of specialisation (i.e. well-matched) and avoid employment that is both in another field and at a lower qualification level. However, the decision process that leads an individual to be matched by field but overqualified or well-matched by qualification 
level but mismatched by field-of-study is unclear. For some recent graduates, particularly in fields that experience high levels of saturation and/or low levels of transferability, the priority might be to find work in the field, even if that means accepting a job with lower qualifications; for others, from fields with high transferability, the priority might be to find work at the appropriate qualification level, even if that means accepting a job in a different field. Moreover, studies that fail to account for qualification mismatch while estimating the field-of-study mismatch wage penalty risk producing biased estimates as part of the marginal penalty associated with field-of-study mismatch have to do with workers having to downgrade in order to find work in other fields rather than to them working in other fields per se (Kim et al. 2012).

This paper attempts to bridge these gaps in the literature by examining how saturation and transferability influence both overqualification and field-of-study mismatch and estimates the respective wage penalties. The following sections describe the data and methods used, including the measures proposed to estimate field saturation and transferability, the results and the main conclusions.

\section{Data}

Data for this study comes from the Programme for International Assessment of Adult Competencies' Survey of Adult Skills (PIAAC). PIAAC is a cross-national survey-24 countries took part in $2012^{2}$-that measures adults' numeracy, literacy and problemsolving in a technology-rich environment. In addition to the assessment, PIAAC asks respondents about their job characteristics, their education and training, their use of different skills at work and home and their socio-demographic characteristics. Given the diversity of participating countries, both the assessment and the background questionnaire were developed and piloted to ensure linguistic and cultural comparability. The PIAAC target population were all non-institutionalised adults aged 16 to 65 (inclusive) who reside in the country at the time of the assessment, regardless of their nationality, citizenship or language. On average across participating countries, a probabilitybased sample of more than 5000 adults was drawn, following population registries or household registries where population registries were unavailable. Depending on the characteristics of each country and its sampling frame, different multistage sampling designs were used; the samples for all countries are representative of the target population (OECD 2013a). Given that mismatch compares the characteristics of the job with individuals' characteristics, the analytical sample $(N=63,772)$ for the study draws on individuals who have graduated from an upper-secondary or higher level (ISCED 3 or higher) with a field-specific programme and who are employed in an occupation that can be related to a specific field-of-study. ${ }^{3}$ Results in this study apply to the population of individuals who graduate from field-specific education programmes and are employed.

Given that PIAAC is a probability sample with different sampling strategies by country, weights are used to make the overall sample representative to the population of workers aged 15 to 64 who are employed in fields other than "general programmes." For country-specific analyses, the estimates are weighted by the full final weight provided in the survey. For pooled analyses, final weights provided in the survey are adjusted so that each country contributes an equal weighted sum of observations, equivalent to the average sample size observed across countries, to prevent countries with larger weighted samples leveraging the results (the USA has an overall weighted 
sum of observations equal to the target population of 203 million, while Estonia is less than one million).

PIAAC uses a complex sampling strategy. As a result, standard errors estimated under the assumption of simple random sampling (as is the case in most standard statistical packages) will be biased. PIAAC provides jackknife-based replicate weights to correctly account for the complex sampling design (OECD 2013a). The estimates presented in this paper take these weights into account through the use of the publicly available "PIAAC Tool" macro. ${ }^{5}$

\section{Methods}

This paper measures field-of-study mismatch, the relationship to overqualification, the relationship to field saturation and transferability and the related wage penalties. The following sections describe these measures and the models to assess their relationships.

\subsection{Field-of-study mismatch and overqualification}

This paper follows Wolbers' (2003) and Quintini's (2011b) approach to the measurement of field-of-study mismatch in a cross-national context, whereby each education degree is categorised in one of nine fields and each ISCO-08 three-digit occupation is matched to one or more fields. In PIAAC, respondents were asked "What was the area of study, emphasis or major for your highest level of qualification? If there was more than one, please choose the one you consider most important" ${ }^{\prime 6}$ with respondents asked to select one of the nine field categories: (i) general programmes; (ii) teacher training and education science; (iii) humanities, languages and arts; (iv) social sciences, business and law; (v) science, mathematics and computing; (vi) engineering, manufacturing and construction; (vii) agriculture and veterinary; (viii) health and welfare and (ix) services. ${ }^{7}$ The question is open to all individuals, irrespective of their level of attainment. Depending on the country, individuals with at most an upper-secondary education degree may report field-specific programmes (e.g. graduates from vocational programmes).

Respondents are also asked an open question about their job title and their responsibilities in the job (both for their current job or the one they last held, if they are currently unemployed or out of the labour force). These descriptions are used to derive each respondent's ISCO-08 three-digit occupation. Using Quintini's (2011b) coding strategy, updated for ISCO-08 codes, each occupation is assigned to one of the nine fields of study (see Appendix 1 for details on the calculation of field-of-study mismatch). Whenever a worker reports having studied in a field that is different than the field(s) that correspond to his/her occupation, the worker is considered to be mismatched by field-of-study. The coding that assigns each occupational code to the corresponding field or fields of study is available in Appendix 1. Under this coding scheme, certain occupations may be matched to more than one field, as a particular occupation may be a relevant destination for graduates from different fields (e.g. an author, journalist or linguist (ISCO-08 code 264) is considered to be matched to his/her field of study if they graduated from the "Humanities, languages and arts" or "Social sciences, business and law" fields). Qualification mismatch is estimated for each individual comparing his or her own educational attainment with their report on the adequate educational level needed to get their job at the time of the survey. Overqualified 
workers are those that have a higher educational attainment than that reported to get their job (Quintini 2011a, 2011b; OECD 2013b).

\subsection{Field saturation}

A field is saturated in the labour market when there are more graduates in the corresponding occupational group relative to the jobs available in the occupational group; if there are few jobs available in an occupational group, workers are forced to search elsewhere for a job. Field saturation is estimated, by the ratio of the number of graduates from a particular field to the number of workers in the corresponding occupational group. Formally, the saturation $S$ of field $f$ in country $c$ can be expressed as

$$
S_{f, c}=\frac{G_{f, c}}{W_{f, c}}
$$

where $G_{f, c}$ is the number of graduates from field $f$ in country $c$ and $W_{f, c}$ is the number of workers currently employed in occupations in occupational group $f$ in country $c$. $G_{f, c}$ is estimated directly from respondents' report to the field-of-study that corresponds to their highest degree and includes individuals both employed and not employed. $W_{f, c}$ is derived from the number of workers in the corresponding occupational group.

As discussed in the measurement of field-of-study mismatch, while the $G_{f, c}$ is based on one-response per respondent, $W_{f, c}$ is based on the attribution that allows for one occupation to belong to more than one field. Given this specification, the indicator has no interpretable scale. It is thus centred at 0 for countries and fields, so that positive (negative) values indicate that, for the specific field, there is higher (lower) saturation than the average field across participating countries. It is standardised to have a standard deviation of 1 across fields and countries, so that a value of $1(-1)$ indicates that the saturation is one standard deviation above (below) the average observed across all fields and countries. ${ }^{8}$

This indicator provides insight on the saturation of a particular field, but is not perfect, particularly because it does not clearly identify the source of the saturation. Ideally, field saturation and shortage would be measured using trends in vacancies or using wage pressure analyses. This information is, however, unavailable in the Survey of Adult Skills or unavailable, using other data sources for all the countries and fields used in this paper. The measure of field saturation also assumes that saturation is constant for all workers within the field. There may be segmentation within the field, however, with saturation present in the occupations that require certain educational attainment, but not for occupations in the occupational group requiring another educational attainment. In the case of "Agriculture and veterinary," for example, the field may be saturated at the professional level, forcing many graduates with university degrees in the field to work in other occupational groups, but the occupational group may face shortages or have low barriers to entry at the lower occupational levels, attracting graduates from other fields with uppersecondary school qualifications specific to other occupational groups.

Appendix 2: Table 3 provides the field saturation indices for each field in each country. 


\subsection{Field transferability}

A field provides transferable skills when workers can work in different fields without having to downgrade. It is determined by the generality/specificity of the skills provided in the field's formal training and the degree to which employers value or recognise skills from other fields (Ormiston 2014). Some research has explored transferability between occupations. These measures can be occupation-based (Shaw 1987) or skill-based (Ormiston 2014), yielding different results but each explaining part of wage gaps associated with occupation changes (Nawakitphaitoon and Ormiston 2016). Though this approach can be extended to fields of study, they impose a unique relationship between occupations across different national contexts. For a comparative study, this is a serious limitation as the labour market and skill development characteristics differ across borders. For example, as a result of the specific curriculum and/or employer's awareness of the value of skills from different fields, workers in Anglo-Saxon countries may be better able to change occupations than workers in other countries, even if they hold a degree from the same field.

This paper draws on the patterns of mobility in each country to estimate the country-specific transferability of each field of study. Field transferability is estimated by the proportion of workers working in another occupational group that are not mismatched in terms of skills or qualifications. Formally, the transferability $T$ of field $f$ in country $c$ can be expressed as

$$
T_{f, c}=\frac{T_{f, c}}{M_{f, c}}
$$

where $T_{f, c}$ is the number of graduates from field $f$ in country $c$ that are working in another field but are well matched by literacy skills and qualifications and $M_{f, c}$ is the number of graduates from field $f$ in country $c$ that are working in another field. Literacy skill match is defined following Pellizzari and Fichen (2013). The high correlation between respondents' scores in literacy, numeracy and problem-solving (OECD 2016) renders literacy skill mismatch a good proxy for workers' information-processing skill mismatch. This skill transferability indicator ranges from 0 to 1 , with values closer to 1 indicating a higher degree of transferability as more workers are able to work in other occupations without downgrading with respect to their qualifications or information-processing skills. This approach to estimating the skill transferability associated with each field of study accounts for differences in the labour market and skill development characteristics of different countries. Models predict the likelihood of mismatch given their field's skill transferability-risk endogeneity. This is particularly the case in country-specific models, but less so in pooled models due to the variability in institutional settings across countries.

This measure of skill transferability is not independent from employers' behaviour. The ability of a worker to be mismatched by field but accurately matched by qualification and literacy skills depends on the transferability of the skills themselves and employers' capacity to identify and/or value transferable skills. ${ }^{9}$

Appendix 2: Table 4 provides the field transferability indices for each field in each country.

\subsection{Model specification}

This paper uses simultaneous regressions (i.e. path analysis in SAS's PROC CALIS) to estimate the relationship between field saturation, field transferability, field-of-study 
mismatch, overqualification and wages. Estimates presented are unstandardized and should be interpreted considering the scale of the variables, just like any regressionbased analyses. To use the complete variability of the PIAAC dataset when accounting for field characteristics, path analyses are run on pooled data. Formally, these models estimate, jointly, the following relationships:

$$
\begin{aligned}
\ln \left(\text { wage }_{i}\right) & =\beta_{0}+\beta_{1} S_{i}+\beta_{2} T_{i}+\beta_{3} F_{i}+\beta_{4} Q_{i}+\beta_{5} F Q_{i}+\beta_{6} N_{i}+X^{\prime} \gamma+Z^{\prime} \boldsymbol{\mu}+\varepsilon_{1 i} \\
F_{i} & =\alpha_{0}+\alpha_{1} S_{i}+\alpha_{2} T_{i}+\alpha_{3} N_{i}+\varepsilon_{2 i} \\
Q_{i} & =\delta_{0}+\delta_{1} S_{i}+\delta_{2} N_{i}+\varepsilon_{3 i} \\
F Q_{i} & =\omega_{0}+\omega_{1} S_{i}+\omega_{2} T_{i}+\omega_{3} F_{i}+\omega_{4} N_{i}+\varepsilon_{4 i}
\end{aligned}
$$

where wage $_{i}$ is the respondents' hourly wages including bonuses in PPP-corrected 2012 USD; $S_{i}$ and $T_{i}$ are the field- and country-specific saturation and transferability measures, respectively, described above; $F_{i}, Q_{i}$ and $F Q_{i}$ are dummy variables indicating whether the respondent is mismatched by field-of-study only, is overqualified only or is mismatched by both field-of-study and overqualified, respectively; $N_{i}$ is the respondent's numeracy skill score and $\mathbf{X}$ is a vector of individual and firm-level controls including age, age-squared, experience, experience-squared, tenure, firm size and dummy variables indicating whether the worker is under a temporary work arrangement, working full time, working in a public organisation or NGO as well as fixed effects for each field of study $(\mathbf{Z})$. Figure 1 below shows these relationships schematically with the resulting estimates.

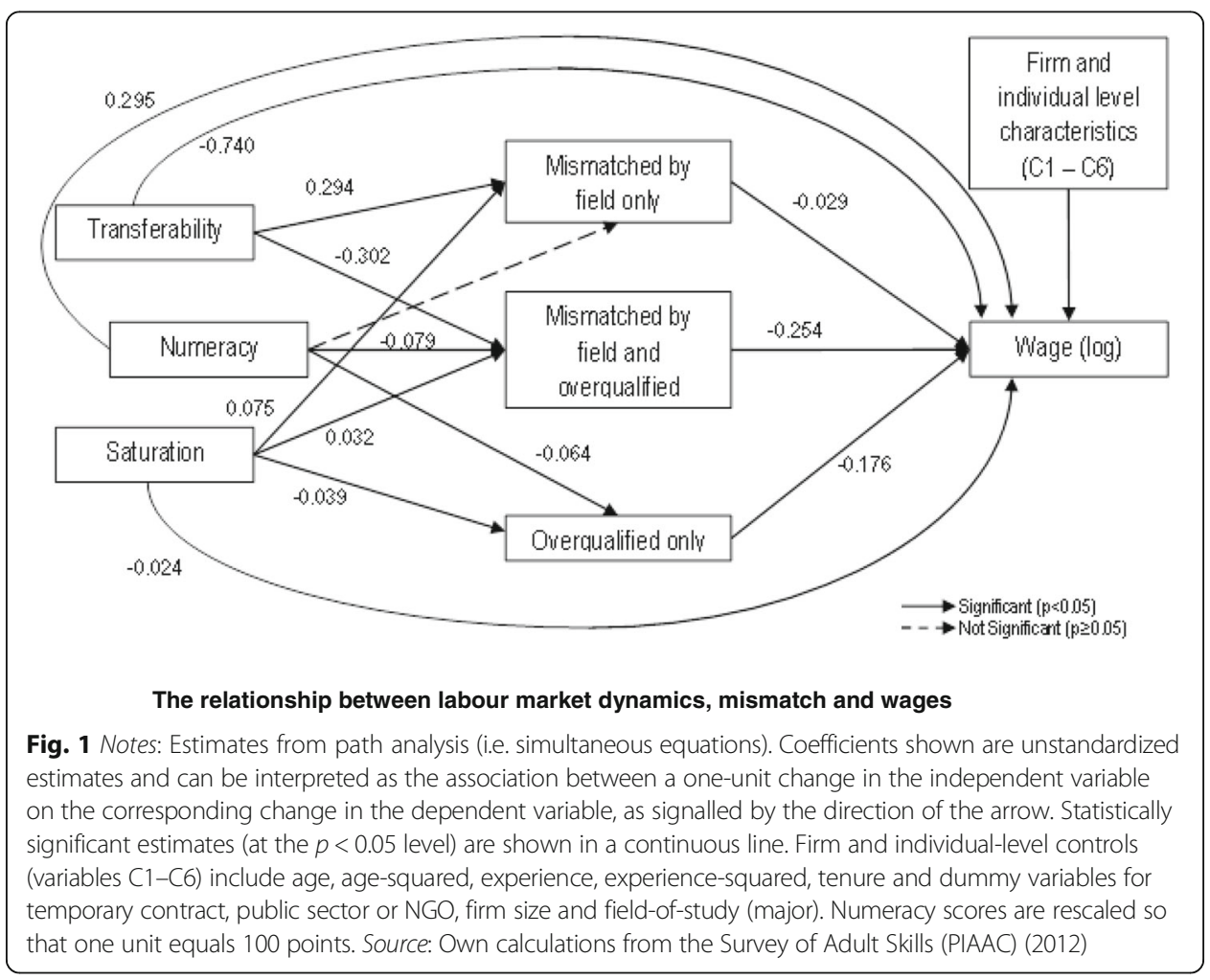


This paper also estimates the following standard wage regressions for each of the participating countries to assess the country-specific mismatch wage penalties. These wage regressions are estimated separately for each country and do not include the transferability $\left(T_{i}\right)$ or saturation $\left(S_{i}\right)$ measures but add, instead, field-specific fixed effects to avoid endogeneity with the mismatch measures:

$$
\ln (\text { wage })_{i}=\beta_{0}+\beta_{1} F_{i}+\beta_{2} Q_{i}+\beta_{3} F Q_{i}+\beta_{4} N_{i}+X^{\prime} \boldsymbol{\gamma}+Z^{\prime} \boldsymbol{\mu}+\varepsilon_{1 i}
$$

All wage regressions exclude observations with wages above the 99th and below the 1st percentile in each country. Missing values on analytical variables have been imputed to the country-specific mean using the dummy-variable imputation method to avoid losing further observations (Allison 2002). It is important to note that the causal implications of these models are limited given the cross-sectional nature of the PIAAC data and the possibility of omitted variable bias. Though models control for numeracy, the issue of skill heterogeneity (Quintini 2011a; Chevalier 2003) may still bias results inasmuch other wage-relevant skill differences between workers with the same qualifications and the same field remain unaccounted. These include, notably, soft and/or social skills (Duncan and Dunifon 2012).

\section{Results}

Table 1 shows the incidence of field-of-study mismatch and overqualification across 23 countries. On average across these countries, 25\% of dependent workers are mismatched by field but working at an adequate qualification level (mismatched horizontally, but not vertically); $11 \%$ are overqualified in their field and 13\% are overqualified and working in another field. Field-of-study mismatch (with or without overqualification) is most likely in Korea (50\%), England/N. Ireland (UK) (50\%), Italy (49\%) and the USA (45\%). It is lowest in Austria, Finland and Germany, at less than 30\%. Field-of-study mismatch is most likely to exist with overqualification in Ireland, Spain, Canada, Japan and France where over $40 \%$ of workers who are field-of-study mismatched are also overqualified. In Poland, Flanders (Belgium) and the Slovak Republic, less than a quarter of field-of-study mismatched workers are also overqualified.

Figure 1 shows the results from the simultaneous regression models. It shows that, as expected, labour market conditions in the form of field saturation and field transferability are associated to the likelihood and type of mismatch. Graduates from fields that offer greater transferability are more likely to be mismatched by field only and less likely to be mismatched and overqualified: these workers seem better able to make horizontal moves without having to downgrade. Graduates from fields that are more saturated are more likely to be working in other fields, both at their qualification level and below their qualification levels; they are also less likely to be overqualified in their own field. That is, graduates from saturated fields are more likely to work in other fields and, often, have to downgrade in order to do so.

Field-of-study mismatched workers face an important wage penalty when field-ofstudy mismatch is accompanied by overqualification; it amounts to $25 \%$ lower earnings compared to their well-matched peers. ${ }^{10}$ For field-mismatched workers that do not downgrade, the penalty is only $3 \%$. These estimates are in line with those observed in the literature (e.g. Robst 2008; Nordin et al. 2010), particularly 
Table 1 Incidence of field-of-study mismatch and overqualification

\begin{tabular}{|c|c|c|c|c|}
\hline Country & $\begin{array}{l}\text { Field-of-study mismatch with } \\
\text { well-matched qualifications }\end{array}$ & $\begin{array}{l}\text { Overqualification with } \\
\text { well-matched field }\end{array}$ & $\begin{array}{l}\text { Field-of-study mismatch } \\
\text { with overqualification }\end{array}$ & $\mathrm{N}$ \\
\hline Austria & $18.1(0.85)$ & $14.2(0.76)$ & $9.7(0.72)$ & 2523 \\
\hline Canada & $21.3(0.56)$ & $13.2(0.48)$ & $15.8(0.59)$ & 10,615 \\
\hline Cyprus ${ }^{\mathrm{a}, \mathrm{b}}$ & $28.7(1.23)$ & $8.7(0.78)$ & $9.7(0.75)$ & 1508 \\
\hline Czech Republic & $27.6(1.26)$ & $11.1(0.97)$ & $10.3(0.85)$ & 2612 \\
\hline Denmark & $24.5(0.73)$ & $8.5(0.54)$ & $10.6(0.61)$ & 3666 \\
\hline England/N. Ireland (UK) & $30.1(0.88)$ & $11.8(0.72)$ & $19.5(1.03)$ & 3714 \\
\hline Estonia & $22.2(0.70)$ & $16.7(0.66)$ & $12.9(0.58)$ & 3217 \\
\hline Finland & $16.1(0.66)$ & $10.9(0.65)$ & $6.5(0.55)$ & 2706 \\
\hline Flanders (Belgium) & $29.4(1.04)$ & $7.9(0.59)$ & $9.1(0.57)$ & 2177 \\
\hline France & $24.2(0.65)$ & $19.5(0.68)$ & $16.6(0.63)$ & 2785 \\
\hline Germany & $15.7(0.68)$ & $14.6(0.81)$ & $9.6(0.59)$ & 2817 \\
\hline Ireland & $22.0(1.02)$ & $13.2(0.91)$ & $19.1(1.15)$ & 1833 \\
\hline Italy & $34.1(1.34)$ & $6.8(0.89)$ & $15.3(1.06)$ & 1450 \\
\hline Japan & $26.2(1.09)$ & $16.9(0.78)$ & $18.6(0.87)$ & 2058 \\
\hline Korea & $34.9(1.13)$ & $7.5(0.61)$ & $15.1(0.86)$ & 1967 \\
\hline Netherlands & $24.3(0.89)$ & $8.8(0.65)$ & $9.5(0.56)$ & 2272 \\
\hline Norway & $22.1(0.90)$ & $9.5(0.59)$ & $11.3(0.60)$ & 2687 \\
\hline Poland & $30.6(1.11)$ & $7.9(0.67)$ & $9.7(0.70)$ & 3393 \\
\hline Russian Federation ${ }^{c}$ & $27.7(1.50)$ & $14.5(0.86)$ & $14.0(1.77)$ & 1599 \\
\hline Slovak Republic & $29.4(1.05)$ & $10.5(0.77)$ & $8.6(0.62)$ & 2408 \\
\hline Spain & $23.6(1.17)$ & $10.2(0.84)$ & $19.5(1.13)$ & 1539 \\
\hline Sweden & $21.8(0.80)$ & $8.6(0.53)$ & $10.8(0.67)$ & 2421 \\
\hline USA & $29.6(1.14)$ & $10.9(0.90)$ & $15.4(0.88)$ & 1805 \\
\hline Country average & $25.4(0.21)$ & $11.4(0.15)$ & $12.9(0.18)$ & 2773 \\
\hline
\end{tabular}

Incidence is calculated over dependent workers. Source: Own calculations from the Survey of Adult Skills (PIAAC) (2012) a Footnote by Turkey: The information in this document with reference to "Cyprus" relates to the southern part of the Island. There is no single authority representing both Turkish and Greek Cypriot people on the Island. Turkey recognises the Turkish Republic of Northern Cyprus (TRNC). Until a lasting and equitable solution is found within the context of United Nations, Turkey shall preserve its position concerning the "Cyprus issue"

${ }^{b}$ Footnote by all the European Union Member States of the OECD and the European Union: The Republic of Cyprus is recognised by all members of the United Nations with the exception of Turkey. The information in this document relates to the area under the effective control of the Government of the Republic of Cyprus

'The data from the Russian Federation are preliminary and may be subject to change. Readers should note that the sample for the Russian Federation does not include the population of the Moscow municipal area. The data published, therefore, do not represent the entire resident population aged 16-65 in Russia but rather the population of Russia excluding the population residing in the Moscow municipal area. More detailed information regarding the data from the Russian Federation as well as that of other countries can be found in the Technical Report of the Survey of Adult Skills (OECD 2013a)

with those that distinguish between field-mismatch and overqualification (Kim et al. 2012). By including workers' numeracy level, these models control for skill heterogeneity (Chevalier 2003; Quintini 2011a).

The estimates in Fig. 1 depict the average worker in the average participating country. As suggested by the relationship to labour market and skill development characteristics, there is cross-national variability in the size of the field-of-study mismatch wage penalty, as shown in Table 2. In fact, the field-of-study mismatch wage penalty among workers who do not downgrade is statistically significant only in Estonia, Ireland and Italy; in the majority of countries, there is no wage penalty for mismatched worker by field who are well qualified in their jobs (the estimate is 
Table 2 The wage penalty of field-of-study mismatch and overqualification

\begin{tabular}{|c|c|c|c|}
\hline Country & $\begin{array}{l}\text { Field-of-study mismatch with } \\
\text { well-matched qualifications }\end{array}$ & $\begin{array}{l}\text { Overqualification with } \\
\text { well-matched field }\end{array}$ & $\begin{array}{l}\text { Field-of-study mismatch } \\
\text { with overqualification }\end{array}$ \\
\hline Austria & $0.00(0.02)$ & $-0.14^{* * *}(0.02)$ & $-0.22^{* * *}(0.03)$ \\
\hline Canada & $-0.02(0.02)$ & $-0.24^{* * *}(0.02)$ & $-0.33^{* * *}(0.02)$ \\
\hline Cyprus $^{\mathrm{a}, \mathrm{b}}$ & $-0.06(0.03)$ & $-0.24^{* * *}(0.05)$ & $-0.37^{* * *}(0.05)$ \\
\hline Czech Republic & $0.00(0.03)$ & $-0.19^{* * *}(0.04)$ & $-0.22^{* * *}(0.04)$ \\
\hline Denmark & $0.02(0.01)$ & $-0.18^{* * *}(0.02)$ & $-0.21^{* * *}(0.02)$ \\
\hline England/N. Ireland (UK) & $-0.01(0.02)$ & $-0.24^{* * *}(0.03)$ & $-0.26^{* * *}(0.03)$ \\
\hline Estonia & $-0.08^{* *}(0.03)$ & $-0.24^{* * *}(0.03)$ & $-0.43^{* * *}(0.03)$ \\
\hline Finland & $0.04^{*}(0.02)$ & $-0.14^{* * *}(0.02)$ & $-0.19^{* * *}(0.03)$ \\
\hline Flanders (Belgium) & $-0.01(0.02)$ & $-0.09^{* * *}(0.03)$ & $-0.17^{* * *}(0.02)$ \\
\hline France & $0.03(0.01)$ & $-0.16^{* * *}(0.02)$ & $-0.16^{* * *}(0.02)$ \\
\hline Germany & $0.00(0.02)$ & $-0.17^{* * *}(0.03)$ & $-0.33^{* * *}(0.04)$ \\
\hline Ireland & $-0.10^{* * *}(0.03)$ & $-0.27^{* * *}(0.03)$ & $-0.34^{* * *}(0.03)$ \\
\hline Italy & $-0.09 * *(0.03)$ & $-0.13^{* *}(0.05)$ & $-0.17^{* * *}(0.04)$ \\
\hline Japan & $0.04(0.03)$ & $-0.21^{* * *}(0.03)$ & $-0.24^{* * *}(0.03)$ \\
\hline Korea & $-0.03(0.03)$ & $-0.22^{* * *}(0.06)$ & $-0.30^{* * *}(0.05)$ \\
\hline Netherlands & $0.00(0.02)$ & $-0.18^{* * *}(0.02)$ & $-0.30^{* * *}(0.04)$ \\
\hline Norway & $0.01(0.02)$ & $-0.16^{* * *}(0.02)$ & $-0.18^{* * *}(0.02)$ \\
\hline Poland & $0.00(0.03)$ & $-0.25^{* * *}(0.04)$ & $-0.31^{* * *}(0.04)$ \\
\hline Russian Federation $^{c}$ & $-0.04(0.04)$ & $-0.08(0.04)$ & $0.00(0.05)$ \\
\hline Slovak Republic & $-0.03(0.03)$ & $-0.20^{* * *}(0.04)$ & $-0.20^{* * *}(0.05)$ \\
\hline Spain & $0.01(0.03)$ & $-0.22^{* * *}(0.04)$ & $-0.26^{* * *}(0.03)$ \\
\hline Sweden & $0.05^{* *}(0.01)$ & $-0.11^{* * *}(0.02)$ & $-0.16^{* * *}(0.02)$ \\
\hline USA & $0.01(0.03)$ & $-0.25^{* * *}(0.04)$ & $-0.30 * * *(0.04)$ \\
\hline Country average & $-0.01 *(0.01)$ & $-0.19^{* * *}(0.01)$ & $-0.25^{* * *}(0.01)$ \\
\hline
\end{tabular}

Estimates from regression models on log(wages). Reference category is well-matched workers who are not overqualified. Models control for age, age ${ }^{2}$, experience, experience ${ }^{2}$, tenure, type of contract (temporary/regular, full/part-time), public/ $\mathrm{NGO/private} \mathrm{sector} \mathrm{of} \mathrm{the} \mathrm{firm,} \mathrm{firm} \mathrm{size,} \mathrm{numeracy} \mathrm{skills} \mathrm{and} \mathrm{field-of-study.}{ }^{*} p<0.05,{ }^{* *} p<0.01$. ${ }^{* * *} p<0.001$. Source: Own calculations from the Survey of Adult Skills (PIAAC) (2012) a, b, c See notes to Table 1

non-significant in 18 countries). In Estonia, Ireland and Italy, the field-of-study mismatch wage penalty without overqualification is around 9\%. In Ireland and Italy, there is a penalty for field-of-study mismatch that does not bring about overqualification, but there is no additional field-of-study penalty when workers are already overqualified. One way to interpret this is that overqualification overrides field-of-study mismatch and field-of-study has little value once workers are overqualified. In Finland and Sweden, mismatched workers by field-of-study who are well matched in terms of occupations tend to earn more than their well-matched field-of-study peers, probably because the most productive mismatched workers by field are attracted by the better salaries in other fields instead of staying in the field they studied or because employers value graduates from different fields equally, so mismatched workers are not penalised by their lack of job-specific skills.

In Austria, Canada, Estonia, Flanders (Belgium), Germany and the Netherlands, the field-of-study mismatch penalty exists only among the overqualified. This is the additional penalty that overqualified workers receive because of field-of-study mismatch; 
it is not the sum of a field-of-study penalty and the overqualification penalty. In Germany and the Netherlands, although field-mismatched workers do not face a penalty when they are matched by qualifications, workers mismatched by field face a penalty of over $12 \%$ if they are overqualified, which comes in addition to the penalty that they expect by virtue of being overqualified to begin with (around 17\%). In Estonia, mismatched workers are sure to face a penalty, whether they are overqualified for the job or not; it amounts to 8 and 19\% for workers who are matched by qualifications and overqualified, respectively.

\section{Conclusions}

All countries experience some level of field-of-study mismatch, with the highest levels observed in Korea, England/N. Ireland (UK) and Italy-at around 50\% of workers-and the lowest in Austria, Germany and Finland-at less than 30\%. Some level of mismatch is expected as individuals look for a job that fits their skills and interests and as economies shift in the types and levels of skill in demand in the labour market. Mismatch is also expected as workers age and career decisions depend more on their past experience than on their formal education. Using data from PIAAC, it is difficult to estimate what proportion of this mismatch is temporary or to what extent mismatch is a transitory stage in workers' careers. Future studies should explore the magnitude and transience of field-of-study mismatch, as well as the long-term consequences for individual workers who enter their careers in a mismatched job, especially if that mismatched job entailed overqualification. Importantly, however, results from this study suggest that field-of-study mismatch need not be considered negative per se, as workers who find a job at their correct qualification level but in another field do not experience a statistically significant wage penalty in most countries.

Field-of-study mismatch is responsive to the broader labour market context; it is not an individual outcome or one that results uniquely from workers' choice. Field saturation is predictive of a higher likelihood of individual field-of-study mismatch. The demand for skills in the labour market is one of the drivers of mismatch: when there are more graduates from a particular field than jobs available in that field, some necessarily need to look elsewhere for a job. Some of these workers may find work in another field for which they are overqualified; others will be adequately matched by their qualifications. The costs of mismatch can be reduced if graduates from saturated fields need not downgrade to jobs with lower qualification requirements or if skill anticipation systems are in place to reduce the likelihood that any given field is highly saturated in the future. Training programmes that recognise skills developed in another field can allow workers from saturated fields to apply their skills to other fields without having to undergo complete training programmes again.

The supply of skills, through the characteristics of the training received, and the labour market's ability to recognise skills from different fields can also drive fieldof-study mismatch. Fields-of-study that provide more transferrable skills offer their graduates more opportunities to find work in other fields and increase the likelihood that in the event of field-of-study mismatch, workers can find jobs at the adequate qualification level, thus reducing the costs associated with field-of-study mismatch. However, the transferability of skills is not equally predictive of field-of- 
study mismatch across all countries, pointing to the articulation of education systems and curricula and the extent to which a particular field provides the same set of general skills across all countries and how credentials are used as signals of worker skills. Such variability is also consistent with the relationship between each field's skill transferability levels and the field-of-study mismatch penalty. This signals that the relationship between skill transferability and wages varies greatly by country, possibly because of the degree to which employers rely on field-of-study as a measure of worker skills or because of the degree of transferability of skills of each field across countries (training for a particular field may be more fieldspecific in one country than another, and/or employers may be more willing and able to recognise skills obtained in another field).

The fact that in most countries, there is no significant wage penalty associated with field-of-study mismatch when workers are not overqualified (Table 2) and that overqualification accounts for only a part of the total field-of-study mismatch (Table 1) suggests that training is already producing sufficient skills to allow at least some, but not all, workers to move across fields at the same qualification level. Investing in retraining or providing alternative career paths so that mismatched workers can earn a credential in a new field at their same qualification level may help the labour market prospects of mismatched workers who are forced to downgrade and also reduce the risks associated to field-of-study mismatch which appear when workers have to downgrade. Encouraging the development of more general skills in training so that workers who are not able to find work in their field-of-study do not have to downgrade to find work may be advisable as is the determination of vacancies in educational programmes in accordance to the current or expected labour market demand. Moreover, encouraging the development of a qualification framework that takes into account workers' flexibility may help employers recognise workers' skills and thus recognise that, for many occupations, a perfect match between field-of-study and occupation is not a requirement for sufficient performance in the job which in turn will allow for graduates from saturated fields to find jobs at their qualification levels in other fields.

Consistent with previous studies, in PIAAC, mismatched individuals experience a wage penalty. It is largely driven by overqualification. Field-of-study mismatch implies, at most and in only a handful of countries, a small penalty for workers, but it is large if workers are forced to take a job that is below their qualification level. Overqualification in or outside the field points to lost productivity related to a lack of job-specific skills (models control for skill heterogeneity) and can aggregate to important national level costs (Mavromaras et al. 2009).

Field-of-study mismatch, though not as problematic when it does not entail overqualification, should be addressed at the policy level because of the consequences it brings to individuals who downgrade and become overqualified. Considering that the bulk of the wage penalty that results from field-of-study mismatch comes from workers' downgrading, facilitating the transferability of workers and skills across fields without having to downgrade (by recognising their skills through comprehensive qualification frameworks or by offering workers and graduates the opportunity to re-skill in a different field while recognising their highest qualification) may help reduce the costs of field-of-study mismatch. 


\section{Endnotes}

${ }^{1}$ McGuinness and Pouliakas (2016) assess human capital attributes (supply), job characteristics and job skill needs (demand) in addition to information assymetries and compensating wage differentials to estimate the overeducation wage penalty. They find support for differences in human capital, job skill requirements, job characteristics and job skill content as explanatory factors behind the wage penalty. They find less support in favour of compensating wage differentials.

${ }^{2}$ For simplicity, throughout this paper, all national entities that took part in PIAAC are referred to as "countries" even though some may not be considered as such under certain definitions (e.g. the Flemish Community of Belgium). Nine additional countries implemented the survey in 2014 but are not included in the analysis to ensure maximum comparability.

${ }^{3}$ Australia is excluded from the analytical sample due to the unavailability of occupation data at the ISCO-08 three-digit level, necessary for the identification of field-of-study mismatch. Following the analytical strategy of Quintini (2011b), of the original 2012 sample that does not include Australia $(N=158,169)$, the analytical sample includes individuals who graduated from a specific educational programme (excluding those with no formal qualification or below ISCED 2; remaining $N=98$ 517), who are employed (remaining $N=75$ 764), who are in the armed forces occupational category (ISCO-08 code 0) or other unclassifiable occupations (chief executives, senior officials and legislators; social and religious professionals; street and market salespersons and manufacturing labourers) or those requiring very minimal training that is not field-specific (subsistence farmers/hunters/fishermen; food preparation assistants; street and related sales and service workers; refuse workers and other elementary workers) (remaining $N=72,285$ ). The analytical sample also excludes individuals with missing information in other analytical variables used as controls in the models (remaining $N=63772$ ).

${ }^{4}$ For the representativity of the analytical sample to this target population, several assumptions must hold among which (a) missing data on any of the analytical variables must be completely at random and (b) the distribution of weights in the sample is invariant to this change in the target population (i.e. the sampling strata are not affected by this change in the definition of the population).

${ }^{5}$ The macro and user documentation is available for SAS and Stata at http:// www.oecd.org/skills/piaac/publicdataandanalysis/.

${ }^{6}$ PIAAC asks about the highest qualification. For individuals with more than one qualification, it is not possible to assess which is the latest one or the one that is most closely related to their job. Certain individuals may have obtained a qualification and went back to education to earn a second, lowest one which more closely matches their career interests. Although impossible to quantify in PIAAC, these cases would be marked as mismatched by field of study when, in practice, they may not experience such mismatch.

${ }^{7}$ Services include fields related to the provision of personal services, transport services, environmental protection and security services.

${ }^{8}$ Models that assume a one-to-one match between occupations and fields in the estimation of saturation yield similar results to those presented in this report (available upon demand). Assuming one-to-one match between occupations adds many 
unverifiable assumptions to the models, reason for which the one-to-many approach was preferred.

${ }^{9}$ It may be the case that for some field-of-study mismatched workers, transferability is high because they have taken further training not captured by their highest educational qualification. Since skill transferability is a measure to characterise fields of study, this situation will bias the skill transferability measure if workers from a particular field are more likely to undergo unobserved training than workers that graduated from another field.

${ }^{10}$ For a mismatched worker, a well-matched peers is one that graduated from the same field and the same level but working in the appropriate field and the appropriate qualification level.

\section{Appendix 1}

\subsection{Linking ISCO-08 occupations to the appropriate field of study}

The following correspondence defines well-matched individuals based on their field-ofstudy (in italics) and ISCO-08 occupation. This list updates the list by Wolbers (2003) and Quintini (2011b) to ISCO-08 codes.

- (2) Teacher training and education science: university, higher education, vocational, secondary, primary, early childhood and other teaching professionals (ISCO 231-235); sports and fitness workers (ISCO 342) and child care workers and teaches' aides (ISCO 531)

- (3) Humanities, languages and arts: university, higher education, vocational and secondary education teaching professionals (ISCO 231-233); architects, planners, surveyors and designers (ISCO 216); librarians, archivists and curators (ISCO 262); social and religious professionals (ISCO 263); authors, journalists and linguists (ISCO 264); creative and performance artists (ISCO 265); legal, social and religious associate professionals (ISCO 341) and artistic, cultural and culinary associate professionals (ISCO 343)

- (4) Social sciences, business and law: directors and chief executives (ISCO 112), managers (ISCO 121-122, 131-134, 141-143); university, vocational and secondary education teaching professionals (ISCO 231-233); business and administration professionals (ISCO 241-243); other health professionals (ISCO 226); legal professionals (ISCO 261); librarians, archivists and curators (ISCO 262); social and religious professionals (ISCO 263); authors, journalists and linguists (ISCO 264); business and administration associate professionals (ISCO 331-335); other health associate professionals (ISCO 325); legal, social and religious associate professionals (ISCO 341); clerical support workers (ISCO 411-413, 421-422, 431-432, 441); sales workers (ISCO 521-524) and street vendors (excluding food) (ISCO 952)

- (5) Science, mathematics and computing: physical and earth science professionals (ISCO 211); mathematicians, actuaries and statisticians (ISCO 212); life science professionals (ISCO 213); other health professionals (ISCO 226); university, vocational and secondary education teaching professionals (ISCO 231-233); Information and communications technology professionals (ISCO 251-252); physical and engineering science technicians (ISCO 311); process control technicians (ISCO 313); life science technicians and related associate professionals (ISCO 314); medical and 
pharmaceutical technicians (ISCO 321); financial and mathematical associate professionals (ISCO 331) and information and communications technicians (ISCO 351-352)

- (6) Engineering, manufacturing and construction: engineering professionals (ISCO 214); electrotechnology engineers (ISCO 215); architects, planners, surveyors and designers (ISCO 216); university, higher education and vocational education teaching professionals (ISCO 231-232); information and communications technology professionals (ISCO 251-252); physical and engineering science technicians (ISCO 311); mining, manufacturing and construction supervisors (ISCO 312); process control technicians (ISCO 313); ship and aircraft controllers and technicians (ISCO 315); regulatory government associate professionals (ISCO 335); information and communications technicians (ISCO 351-352); building and housekeeping supervisors (ISCO 515); crafts and related trades workers (ISCO 711-713, 721723, 731-732, 741-742, 751-754); plant and machine operators and assemblers (ISCO 811-818, 821, 831-835) and labourers in mining, construction, manufacturing and transport (ISCO 931-933)

- (7) Agriculture and veterinary: life science professionals (ISCO 213); veterinarians (ISCO 225); university, higher education and vocational education teaching professionals (ISCO 231-232); life science technicians and related associate professionals (ISCO 314); medical and pharmaceutical technicians (ISCO 321); veterinary technicians and assistants (ISCO 324); other health associate professionals (ISCO 325); skilled agricultural, forestry and fishery workers (ISCO 611-613, 621622, 631-634); food processing and related trades workers (ISCO 751); other craft and related workers (ISCO 754); mobile plant operators (ISCO 834) and agricultural, forestry and fishery labourers (ISCO 921)

- (8) Health and welfare: life science professionals (ISCO 213), health professionals (ISCO 221-227); university and higher education teaching professionals (ISCO 231); primary school and early childhood teachers (ISCO 234); social and religious professionals (ISCO 263); health associate professionals (ISCO 321-325); legal, social and religious associate professionals (ISCO 341); other personal service workers (ISCO 516); personal care workers (ISCO 531-532) and protective services workers (ISCO 541)

- (9) Service: professional services managers (ISCO 134); sales, marketing and public relations professionals (ISCO 243); other health associate professionals (ISCO 325); administrative and specialised secretaries (ISCO 334); regulatory government associate professionals (ISCO 335); legal, social and religious associate professionals (ISCO 341); artistic, cultural and culinary associate professionals (ISCO 343); clerical support workers (ISCO 411-413, 421-422, 431-432, 441); service and sales workers (ISCO 511-516, 521-524, 531-532, 541); drivers and mobile plant operators (ISCO 831-835); cleaners and helpers (ISCO 911-912); food preparation assistants (ISCO 941); street and related service workers (ISCO 951) and street vendors (excluding food) (ISCO 952)

- Coded as missing: all self-employed workers and those who majored in "general programmes"; armed forces occupations (ISCO major group 0); legislators and senior officials (ISCO 111) and refuse workers and other elementary workers (ISCO 961-962) 


\section{Appendix 2}

\subsection{Field saturation and field transferability}

Table 3 Field saturation across countries

\begin{tabular}{|c|c|c|c|c|c|c|c|c|}
\hline & \multicolumn{8}{|c|}{ Field saturation } \\
\hline & (2) & (3) & (4) & (5) & (6) & (7) & (8) & (9) \\
\hline Austria & 0.3 & -0.5 & 0.0 & -1.2 & 1.1 & -0.4 & -0.5 & -0.9 \\
\hline Canada & 0.2 & 0.9 & -0.7 & 0.7 & -0.3 & -1.2 & -0.1 & -1.2 \\
\hline Cyprus ${ }^{\mathrm{a}, \mathrm{b}}$ & 0.3 & 1.1 & -0.8 & 0.9 & 0.2 & -1.2 & -0.7 & -1.2 \\
\hline Czech Republic & 0.9 & 0.6 & -0.3 & -1.0 & 1.1 & 0.8 & -0.9 & -0.8 \\
\hline Denmark & 0.7 & 0.4 & -0.5 & -0.1 & 0.2 & -0.4 & -0.3 & -0.8 \\
\hline England/N. Ireland (UK) & -0.1 & 5.1 & -0.4 & 1.3 & 0.0 & -1.0 & -0.6 & -1.6 \\
\hline Estonia & 0.1 & 0.1 & -0.5 & -0.5 & 0.4 & 0.1 & -0.5 & -0.9 \\
\hline Finland & 0.1 & -0.2 & -0.3 & -1.1 & 0.7 & -0.3 & 0.3 & -1.1 \\
\hline Flanders (Belgium) & 0.5 & 0.6 & -0.7 & 0.8 & 0.7 & -0.5 & 0.2 & -1.4 \\
\hline France & -0.2 & 0.0 & -0.6 & 0.5 & 0.1 & -0.2 & 0.1 & -0.6 \\
\hline Germany & -0.1 & -0.3 & 0.0 & -0.5 & 1.0 & -0.8 & 0.3 & -1.2 \\
\hline Ireland & 0.4 & 1.1 & -0.3 & 1.9 & 0.2 & -0.4 & -0.1 & -1.1 \\
\hline Italy & -0.3 & 3.1 & -0.6 & 1.4 & -0.2 & -0.2 & -0.5 & -1.1 \\
\hline Japan & 2.0 & 1.6 & -0.9 & -0.9 & 0.2 & -0.4 & -0.5 & -1.4 \\
\hline Korea & -0.1 & 1.6 & -0.9 & 2.8 & 0.2 & -0.1 & -0.5 & -1.5 \\
\hline Netherlands & 0.3 & -0.5 & -0.2 & -0.1 & 0.5 & -0.1 & 0.5 & -1.4 \\
\hline Norway & 0.0 & 0.1 & -0.3 & 0.1 & 1.2 & -0.7 & -0.2 & -1.4 \\
\hline Poland & 0.5 & 1.0 & -0.7 & 0.2 & 0.9 & -0.3 & -0.8 & -0.7 \\
\hline Russian Federation ${ }^{c}$ & 1.1 & 1.1 & -1.0 & 0.4 & 0.4 & 0.3 & -0.8 & -1.0 \\
\hline Slovak Republic & 0.7 & 0.9 & -0.7 & 0.3 & 0.8 & 1.1 & -0.5 & -0.5 \\
\hline Spain & 0.1 & 1.9 & -0.4 & 1.0 & 0.6 & -1.0 & -0.1 & -1.4 \\
\hline Sweden & 0.4 & 0.4 & -0.2 & -0.8 & 0.7 & -0.4 & 0.0 & -1.3 \\
\hline USA & 0.8 & 1.0 & -0.4 & 1.3 & -0.3 & -1.3 & 0.2 & -1.2 \\
\hline Country average & 0.4 & 0.9 & -0.5 & 0.3 & 0.5 & -0.4 & -0.3 & -1.1 \\
\hline
\end{tabular}

Source: Own calculations based on the Survey of Adult Skills (PIAAC) (2012)

(2) teacher training and education science, (3) humanities, languages and arts, (4) social sciences, business and law, (5) science, mathematics and computing, (6) engineering, manufacturing and construction, (7) agriculture and veterinary, (8) health and welfare, (9) service. ${ }^{a}$, b, c See notes to Table 1 
Table 4 Field transferability across countries

\begin{tabular}{|c|c|c|c|c|c|c|c|c|}
\hline & \multicolumn{8}{|c|}{ Field transferability } \\
\hline & (2) & (3) & (4) & (5) & (6) & (7) & (8) & (9) \\
\hline Austria & 0.5 & 0.5 & 0.4 & 0.5 & 0.5 & 0.5 & 0.4 & 0.4 \\
\hline Canada & 0.5 & 0.5 & 0.4 & 0.5 & 0.6 & 0.4 & 0.4 & 0.4 \\
\hline Cyprus $^{\mathrm{a}, \mathrm{b}}$ & 0.6 & 0.5 & 0.4 & 0.6 & 0.7 & 0.2 & 0.5 & 0.6 \\
\hline Czech Republic & 0.5 & 0.4 & 0.4 & 0.6 & 0.6 & 0.5 & 0.4 & 0.5 \\
\hline Denmark & 0.7 & 0.5 & 0.4 & 0.5 & 0.5 & 0.4 & 0.7 & 0.5 \\
\hline England/N. Ireland (UK) & 0.5 & 0.4 & 0.4 & 0.4 & 0.5 & 0.6 & 0.4 & 0.9 \\
\hline Estonia & 0.6 & 0.6 & 0.4 & 0.5 & 0.5 & 0.5 & 0.6 & 0.6 \\
\hline Finland & 0.6 & 0.4 & 0.5 & 0.7 & 0.7 & 0.6 & 0.6 & 0.4 \\
\hline Flanders (Belgium) & 0.6 & 0.6 & 0.6 & 0.6 & 0.5 & 0.6 & 0.6 & 0.5 \\
\hline France & 0.6 & 0.3 & 0.3 & 0.5 & 0.6 & 0.4 & 0.4 & 0.3 \\
\hline Germany & 0.6 & 0.6 & 0.3 & 0.6 & 0.5 & 0.4 & 0.4 & 0.5 \\
\hline Ireland & 0.3 & 0.3 & 0.4 & 0.5 & 0.4 & 0.5 & 0.4 & 0.6 \\
\hline Italy & 0.5 & 0.4 & 0.4 & 0.5 & 0.5 & 0.3 & 0.2 & 0.4 \\
\hline Japan & 0.5 & 0.4 & 0.3 & 0.5 & 0.5 & 0.5 & 0.4 & 0.4 \\
\hline Korea & 0.5 & 0.6 & 0.5 & 0.6 & 0.7 & 0.5 & 0.6 & 0.3 \\
\hline Netherlands & 0.4 & 0.4 & 0.5 & 0.6 & 0.7 & 0.8 & 0.6 & 0.7 \\
\hline Norway & 0.6 & 0.4 & 0.4 & 0.4 & 0.5 & 0.3 & 0.5 & 0.4 \\
\hline Poland & 0.6 & 0.5 & 0.4 & 0.6 & 0.7 & 0.7 & 0.4 & 0.8 \\
\hline Russian Federation ${ }^{c}$ & 0.5 & 0.5 & 0.3 & 0.7 & 0.5 & 0.5 & 0.5 & 0.5 \\
\hline Slovak Republic & 0.5 & 0.6 & 0.6 & 0.7 & 0.7 & 0.7 & 0.5 & 0.6 \\
\hline Spain & 0.3 & 0.4 & 0.2 & 0.4 & 0.4 & 0.6 & 0.4 & 0.6 \\
\hline Sweden & 0.5 & 0.4 & 0.3 & 0.4 & 0.5 & 0.5 & 0.6 & 0.6 \\
\hline USA & 0.6 & 0.5 & 0.5 & 0.6 & 0.5 & 0.4 & 0.4 & 0.4 \\
\hline Country average & 0.5 & 0.5 & 0.4 & 0.5 & 0.6 & 0.5 & 0.5 & 0.5 \\
\hline
\end{tabular}

Source: Own calculations based on the Survey of Adult Skills (PIAAC) (2012)

(2) teacher training and education science, (3) humanities, languages and arts, (4) social sciences, business and law, (5) science, mathematics and computing, (6) engineering, manufacturing and construction, (7) agriculture and veterinary, (8) health and welfare, (9) service. ${ }^{a}$, b, c See notes to Table 1

\section{Acknowledgements}

The author thanks Glenda Quintini, Paulina Granados, two anonymous reviewers and the editor for their insightful comments. A version of this paper was presented at the 10th IZA/World Bank Conference on Employment and Development held in June 2015 and published as OECD Social, Employment and Migration Working Paper No. 167 (http://dx.doi.org/10.1787/5jrxm4dhv9r2-en). The responsibility for opinions expressed in this article rests solely with its author, and publication does not constitute an endorsement by the International Labour Office of the opinions expressed in it

Responsible editor: Joni Hersch

\section{Competing interests}

The IZA Journal of Labor Economics is committed to the IZA Guiding Principles of Research Integrity. The author declares that he has observed these principles.

Received: 27 September 2016 Accepted: 14 December 2016

Published online: 30 January 2017

\section{References}

Allison P (2002) Missing data. Sage Publications, Thousand Oaks

Béduwé C, Giret J (2011) Mismatch of vocational graduates: what penalty on French labour market? J Vocat Behav 78 : 68-79

CEDRA (2009) Skill mismatch: identifying priorities for future research. Working Paper 3. Cedefop, Thessalonik Chevalier A (2003) Measuring over-education. Economica 70:509-531

Duncan G, Dunifon R (2012) Soft-skills and long-run labor market success. Res Labor Econ 35:313-339 
García-Aracil A, van der Velden R, (2008) Competencies for young European higher education graduates: labor market mismatches and their payoffs. Higher Education 55(2):219-239.

Hartog J (2000) Over-education and earnings: where are we, where should we go? Econ Educ Rev 19:131-147

Humburg M, van der Velden R, Verhagen A (2013) The employability of higher education graduates: the employers' perspective. Publications Office of the European Union, Brussels

Kelly E, O'Connell P, Smyth E (2010) The economic returns to field-of-study and competencies among higher education graduates in Ireland. Econ Educ Rev 29:650-657

Kim H, Ahn S, Kim J (2012) Vertical and horizontal education-job mismatches in the Korean youth labor market: a quantile regression approach. Working Papers 1201, Research Institute for Market Economy, Sogang University

Levels M, van der Velden R, Allen J (2014) Educational mismatches and skills: new empirical tests of old hypotheses. Oxf Econ Pap 66:959-982

Mavromaras K, McGuinness S, Fok Y (2009) Assessing the incidence and wage effects of overskilling in the Australian labour market. Econ Rec 85:60-72

McGuinness S, Pouliakas K (2016) Deconstructing theories of overeducation in Europe: a wage decomposition approach. IZA Discuss Pap 9698.

McGuinness S, Sloane P (2011) Labour market mismatch among UK graduates: an analysis using REFLEX data. Econ Educ Rev 30:130-145

Nawakitphaitoon K, Ormiston R (2016) The estimation methods of occupational skills transferability. J Labor Mark Res. doi:10.1007/s12651-016-0216-y

Nordin M, Persson I, Rooth D (2010) Education-occupation mismatch: is there an income penalty? Econ Educ Rev 29: $1047-1059$

OECD (2013a) Technical report of the Survey of Adult Skills (PIAAC) [PRE-PUBLICATION COPY]. OECD Publishing, Paris, doi:10.1787/9789264204027-3-en

OECD (2013b) OECD skills outlook 2013: first results from the Survey of Adult Skills. OECD Publishing, Paris, doi:10.1787/ 9789264204256-en

OECD (2014) OECD employment outlook 2014. OECD Publishing, Paris, doi:10.1787/empl_outlook-2014-en

OECD (2016) Skills matter: further results from the Survey of Adult Skills. OECD Publishing, Paris, doi:10.1787/ 9789264258051-en

Ormiston R (2014) Worker displacement and occupation-specific human capital. Work Occup 41:350-384

Ortiz L, Kucel A (2008) Do fields of study matter for over-education? The cases of Spain and Germany. Int J Comp Sociol 49:305-327

Pellizzari M, Fichen A (2013) A new measure of skills mismatch: theory and evidence from the Survey of Adult Skills (PIAAC). OECD Soc Employ Migr Work Paps, 153, doi:10.1787/5k3tpt04lent-en

Quintini G (2011a) Over-qualified or under-skilled: a review of existing literature, OECD Soc Employ Migr Work Pap, doi: $10.1787 / 5 \mathrm{~kg} 58 \mathrm{j} 9 \mathrm{~d} 7 \mathrm{~b} 6 \mathrm{~d}-\mathrm{en}$

Quintini G (2011b) Right for the job: over-qualified or under-skilled? OECD Soc Employ Migr Work Pap, doi:10.1787/ $1815199 X$

Robst J (2007a) Education and job match: the relatedness of college major and work. Econ Educ Rev 26:397-407

Robst J (2007b) Education, college major, and job match: gender differences in reasons for mismatch. Educ Econ 15: $159-175$

Robst J (2008) Overeducation and college major: expanding the definition of mismatch between schooling and jobs. Manch Sch 76:349-368

Sattinger M (1993) Assignment models of the distribution of earnings. J Econ Lit 31:831-880

Shaw K (1987) Occupational change, employer change, and the transferability of skills. South Econ J 53:702-719

Sloane P (2003) Much ado about nothing? What does the overeducation literature really tell us. In: Büchel F, de Grip A, Mertens A (eds) Overeducation in Europe: current issues in theory and policy. Edward Elgar Publishing, Cheltenham, pp 11-45

Van de Werhorst H (2002) Field of study, acquired skills and wage benefits from a matching job. Acta Sociol 25:286-303 Verhaest D, van der Velden R (2013) Cross-country differences in graduate overeducation. Eur Sociol Rev 29:642-653 Verhaest D, Sellami S, van der Velden R (2013) Differences in horizontal and vertical mismatches across countries and fields of study. Studie-en Schoolloopbanen, Brussels

Wolbers M (2003) Job mismatches and their labour-market effects among school-leavers in Europe. Eur Sociol Rev 19 249-266

\section{Submit your manuscript to a SpringerOpen ${ }^{\circ}$ journal and benefit from:}

- Convenient online submission

- Rigorous peer review

- Immediate publication on acceptance

- Open access: articles freely available online

- High visibility within the field

- Retaining the copyright to your article

Submit your next manuscript at $>$ springeropen.com 